\title{
Factors of psychological well-being of adolescents in the aspect of self-knowledge
}

\author{
Inessa Leonidovna Feldman ${ }^{1 *}$, Valery Sergeevich Agapov ${ }^{2}$, Svetlana Vasilyevna \\ Feoktistova $^{3}$, and Oksana Ivanovna Griboyedova ${ }^{4}$ \\ ${ }^{1}$ Tula State University, Institute of Humanities and Social Sciences, Department of Psychology, Tula, \\ Russia \\ ${ }^{2} \mathrm{~V}$. Ya. Kikot Moscow University of the Ministry of Internal Affairs of the Russian Federation, \\ Department of Legal Psychology of the Educational and Scientific Complex of Psychology of \\ Official Activity, Moscow, Russia \\ ${ }^{3}$ Russian New University, Institute of Psychology and Pedagogy, Department of General Psychology \\ and Labor Psychology, Moscow, Russia \\ ${ }^{4}$ L. N. Tolstoy State Pedagogical University, Faculty of Psychology, Department of Psychology and \\ Pedagogy, Tula, Russia
}

\begin{abstract}
The premise for the present study lies in the lack of a unanimous scientific opinion on the relationship between self-knowledge and psychological well-being. The article presents the results of a study of the factors of psychological well-being of adolescents associated with their selfknowledge. The relevance of the conducted study is due to the need to integrate scientific knowledge on the internal factors contributing to psychological well-being. The scientific novelty is shaped by the fact that adolescents' self-knowledge in the context of their psychological well-being is understudied and is examined for the first time. The study includes 500 adolescents aged 13-17 years old from schools in Tula, Lipetsk, and Moscow regions. The conducted factor analysis reveals common and specific factors of psychological well-being that are significant for adolescents with varying levels of psychological well-being. The common factors found in the entire sample are the desire for self-reflective analysis, for successful communication, for physical harmony, and for a meaningful perception of one's future. The specific factors relevant for each group - adolescents with high, average, and low levels of psychological well-being - are also identified. The results of the analysis allow concluding that the psychological well-being of adolescents at different levels of psychological well-being is determined by factors related to self-knowledge. The presented work is of interest for researchers concerned with the problems of adolescents' psychological well-being, as well as in designing educational programs and projects aimed at improving the psychological well-being of adolescents.
\end{abstract}

Keywords: psychological well-being, factor, self-knowledge, adolescents.

\footnotetext{
* Corresponding author: inessa-feldman@mail.ru
} 


\section{Introduction}

New tasks associated with the upbringing of a harmoniously developed personality are currently being set at the level of state policy in the sphere of education, special attention is paid to preserving psychological health and promoting the psychological well-being of students. One of the mechanisms for the implementation of these tasks is the development of psychological services in the educational system and scientific research into the psychological well-being of children and adolescents.

Understanding the importance of adolescence in personality development and the creation of the basic foundations of human well-being, modern scientists continue research on the psychology of adolescents [1-7]. Nevertheless, the issues of the internal factors and mechanisms of the formation of adolescents' psychological well-being remain underexplored in modern science.

In recent decades, there were numerous attempts to understand what a modern adolescent is like and what helps them achieve psychological well-being. Some researchers found the answer to this question describing the results of the study of relationships between psychological, subjective well-being, life satisfaction and the self-concept, self-esteem, awareness, and reflexivity of adolescents [8-14]. Others have explored factors and conditions for improving adolescents' psychological well-being: knowledge of their family history [15], positive relationships with parents and friends [16], emotional intelligence [1], faith in God, people, nature, and themselves as sources of justice [17], the amount of personal time and personal space [18], and social activity [19]. Researchers define a psychologically well teenager as a person who has internal harmony, which is provided by self-awareness, selfknowledge, and self-regulation. The role of self-knowledge is key in this case as it is this process that assists adolescents' self-development, self-change, and self-improvement.

Therefore, the study of adolescents' self-knowledge and its role in the formation of psychological well-being is of crucial scientific importance in determining the foundations and mechanisms of adolescents' well-being.

As part of our study of the characteristics of self-knowledge of adolescents with different levels of psychological well-being, the purpose of the present article is to present the results on the identified factors related to adolescents' self-knowledge that affect their psychological well-being.

\section{Methods}

The empirical study was conducted on a sample of 500 adolescents aged 13-17 from the Tula, Lipetsk, and Moscow regions who were divided into the groups of high, average, and low levels of psychological well-being.

Adolescents' psychological well-being was assessed using the following methods: K. Riff's scale of psychological well-being (as adapted by T.D. Shevelenkova, P.P. Fesenko), the life satisfaction index (N.V. Panina), the subjective well-being scale (as adapted by M.V. Sokolova), and the personal anxiety scale (A.M. Prikhozhan).

The characteristics of self-knowledge were studied using the self-awareness needs questionnaire (A.V. Kalashnik), the reflexivity questionnaire (A.V. Karpov, V.V. Ponomareva), the "Who am I" method (M. Kuhn, T. McPartland, as modified by T.V. Rumiantseva), the self-attitude questionnaire (V.V. Stolin, S.R. Pantileev), self-esteem questionnaire (G.N. Kazantseva), the self-regulation style questionnaire (V.I. Morosanova), and the self-presentation strategy questionnaire (I.P. Shkuratova).

To identify factors related to adolescents' self-knowledge that affect their psychological well-being, we conducted a factor analysis of 59 attributes selected through principal component analysis using the SPSS 21.0 software package. 
Factor analysis using the varimax-rotation procedure with Kaiser's normalization (rotation converged for 25 iterations) allows us to establish the nature of the relationship between the parameters of adolescents' self-knowledge and their psychological well-being in the studied groups of respondents. We view the identified factors as foundations for the experience of psychological well-being related to self-knowledge.

\section{Results}

The conducted factor analysis allows us to identify 6 factors with a total variance of $100 \%$ in the group of adolescents with a high level of psychological well-being. We define them as "striving for social significance", "striving for self-acceptance through self-knowledge", "striving for self-reflective analysis", "striving for confident communication", "striving for physical harmony", and "striving for a meaningful perception of the future".

The observed correlations and the contents of the identified factors, where the image of the "active self" is present in four different factors, allow us to state that reflection of one's activities and the perception of oneself as a source of one's own activity is a distinctive feature of adolescents high in well-being and their positive attitude towards themselves and self-management (highly significant in three factors) can be considered as factors of psychological well-being in this group.

In the group of adolescents with an average level of psychological well-being, factor analysis revealed 16 factors with a total (cumulative) variance of $75.5 \%$. The factors providing a more significant contribution to the total variance are what we identify as "striving to know oneself", "striving for positive self-perception", "striving for satisfaction with health", "striving for self-reflective analysis", "striving for successful communication", "striving to understand oneself as a source of one's own activity", "striving to be accepted by others", "striving for successful activity with a positive attitude towards and acceptance of oneself", "striving for a meaningful perception of one's future", "striving for selfperception through the feeling of oneself as an owner of material goods", "striving for adequacy of self-blame", and "striving for physical harmony".

The detected correlations and the content of the identified factors, where the expected attitude from others, self-sympathy, and self-acceptance are present in several different factors, allow us to state that the desire to be understood and accepted by others that improves self-sympathy and self-acceptance can be considered as a factor of psychological well-being of adolescents in this level group.

In the group of adolescents with a low level of psychological well-being, factor analysis shows 15 factors with a total (cumulative) variance of $83.8 \%$. Here we present the factors providing the most significant contribution to the total variance. We define these factors as "striving to know oneself", "striving for physical harmony", "striving to understand oneself as a source of activity in one's life", "striving to feel one's significance for oneself and others", "striving for self-reflexive analysis", "striving for confidence in activity", "striving for successful communication", "striving for a meaningful perception of one's future”, "striving for adequacy of self-blame", "striving for understanding oneself and others", and "striving for self-acceptance".

The discovered correlations and the contents of the highlighted factors, where the "physical self" identification characteristic is present in several different factors, allow us to conclude that an adolescent's striving to experience physical integrity and concerns about its violation or imperfection can be considered as factors of psychological well-being of adolescents in this group.

It is important to note that the analysis of the factor matrix constructed for the total sample of adolescents demonstrates special importance of such variables as reflection of communication and interaction with other people, self-respect, a positive attitude towards 
oneself, self-acceptance, the characteristics of the "reflective self", "physical self", and selfesteem for understanding the interrelation of adolescents' self-knowledge and psychological well-being.

\section{Discussion}

Analysis of the obtained results reveals similarities and differences in factors associated with self-knowledge as the foundations of the experience of psychological well-being in adolescents of different level groups.

Factors found to be common for adolescents across all level groups are the ones associated with striving for self-reflective analysis, striving for successful communication, the feeling of physical harmony, and striving for a meaningful perception of one's future. The indication of these factors testifies to the importance of these characteristics for adolescents' experience of life satisfaction, subjective well-being, and psychological wellbeing overall.

The study also reveals similar factors for adolescents with average and low levels of psychological well-being. The results show the relationship of the psychological well-being of these respondents with their striving to know themselves, to be satisfied with their health, to understand themselves as a source of their own activity, to be accepted and significant to others, and striving for the adequacy of self-blame. The significance of these factors in these level groups and their absence in adolescents with a high level of psychological well-being can explain the lower level of psychological well-being in these respondents. It is possible to assume that the lack of expression of these characteristics related to self-knowledge leads to adolescents' feeling of personal deficits that they strive to compensate for to achieve greater psychological well-being.

Of particular interest are the factors specific to each level group of adolescents identified as a result of our analysis that show differences in the foundations of the experience of psychological well-being associated with self-knowledge in adolescents with high, average, and low levels of psychological well-being. These factors turned out to be:

- in adolescents with a high level of psychological well-being - striving for social significance against the background of a positive attitude towards and respect for oneself and striving for self-acceptance through self-knowledge,

- in adolescents with an average level of psychological well-being - striving for positive self-perception, striving for successful activity against the background of a positive attitude towards and acceptance of oneself, striving to perceive oneself as the owner of material goods,

- in adolescents with a low level of psychological well-being - striving to feel one's importance for themselves and others, striving for confidence in activity, striving to understand oneself and others, and striving for self-acceptance through a positive attitude towards oneself and physical harmony.

The findings suggest that adolescents with different levels of psychological well-being demonstrate a particular significance of factors reflecting their deficits in terms of selfknowledge that inhibited their psychological well-being at the time of the study.

\section{Conclusion}

To summarize, we can state that the psychological well-being of adolescents with different levels of psychological well-being is determined by common and specific factors related to self-knowledge. 
The prospects for the present study include the development of a program to improve the psychological well-being of adolescents through the development of components of their self-knowledge, as well as a more detailed study of the personal characteristics of adolescents from different psychological well-being level groups.

\section{References}

1. S.A. Vodiakha, Iu.E. Vodiakha, Pedagogical Education in Russia, 1, 103-108 (2020)

2. I.V. Dubrovina, Bulletin of Psychological Practice in Education, 2(51), 44-52 (2017)

3. M.V. Danilova, L.V. Rykman, Psychological Science and Education, 23(5), 40-50 (2018). https://doi.org/10 .17759/pse .2018230505.

4. D. I. Dubrov, Kazan Pedagogical Journal, 6, 184-190 (2016)

5. A. V. Mikliaeva, V. V. Khoroshikh, E. N. Volkova, Science for Education Today, 4, 36-55 (2019)

6. A. A. Rean, I. L. Shagalov, Voprosy Psikhologii [Questions of Psychology], 6, 16-28 (2018)

7. E. A. Sorokoumova, A. L. Tsyntsar, Podrostki v distantnykh semiakh: stanovlenie samosoznaniia [Adolescents in estranged families: the formation of self-consciousness] (Moscow State Pedagogical University, Moscow, 2019)

8. M.Iu. Bondareva, E.N. Tkach, Acmeology, 1-2, 216-218 (2014)

9. S. B. Klein, J. F. Kihlstrom, J. Loftus, Preserved and impaired self-knowledge in amnesia: A case study. Unpublished manuscript (2000)

10. V.M. Byzova, Iu.A. Kalashnikova, Psikhicheskaia regidnost i refleksivnost kak faktory psikhologicheskogo blagopoluchiia [Mental regidity and reflexivity as factors of psychological well-being], in A.V. Shabolas, N.V. Grishina et al. (Eds.), Proceedings of the International Scientific Conference "Ananiev Readings - 2016: Psychology: Yesterday, Today, Tomorrow”, 5-6 (Saint Petersburg, 2016)

11. L.V. Kosikova, Psychology of Education, 1, 124 (2019)

12. O.D. Pugovkina, Z.N. Shilnikova, Journal of Modern Foreign Psychology, 3(2), 18-28 (2014)

13. J. Hoyer, A. Klein, Psychol Rep, 86(1), 35-41 (2000). https://doi.org/10.2466/pr0.2000.86.1.135

14. J. Schneider, Psychological Reports, 91(3), 807-813 (2002)

15. T.V. Iakimova, Ia.A. Bondarenko, Psychological-Educational Studies, 6(4), 93-105 (2014). https://doi.org/10.17759/psyedu.2014060409

16. O.A. Idobaeva, A.I. Podolskii, Psikhologicheskoe blagopoluchie sovremennykh podrostkov: aktualnyi uroven i puti ego povysheniia [Psychological well-being of modern adolescents: current level and ways of improving it] (Eko-Press, Moscow, 2012)

17. N.B. Astanina, Clinical Psychology and Special Education, 5(4), 26-38 (2016). https://doi.org/10.17759/psyclin.2016050402.

18. O.V. Silina, Clinical Psychology and Special Education, 5(3), 116-129 (2016). https://doi.org/10.17759/ cpse.2016050308.

19. E.E. Bocharova, Social Psychology and Society, 4, 53-63 (2012) 